\title{
An Examination of Adverse Selection in the Public Provision of Insurance
}

\author{
Randy E. Dumm ${ }^{\mathrm{a}}$, David L. Eckles ${ }^{\mathrm{b}}$ and Martin Halek ${ }^{\mathrm{c}}$ \\ ${ }^{a}$ Florida State University, Tallahassee, FL, U.S.A. \\ ${ }^{\mathrm{b}}$ University of Georgia, 206 Brooks Hall, Athens, GA 30602, U.S.A. \\ E-mail: deckles@uga.edu \\ ${ }^{\mathrm{c}}$ University of Wisconsin, Madison, WI, U.S.A.
}

Using a unique data set from Florida's residual property insurer, we test for adverse selection in the public provision of homeowners' insurance in Florida. We find a significant relationship between the losses and deductible choices of insureds in Florida's residual homeowners' insurance market. This relationship provides strong evidence of the existence of an adverse selection problem in Florida's residual property insurance market. While this relationship is important to Florida regulators (and taxpayers) specifically, a finding of an adverse selection problem in residual markets in general has implications more broadly for government providers of insurance as an adverse selection problem in these settings will impact the public policy debates and decisions involving these markets.

The Geneva Risk and Insurance Review (2013) 38, 127-147. doi:10.1057/grir.2013.1

Keywords: regulated markets; adverse selection; public insurance

Article submitted 31 May 2011; accepted 9 January 2013; published online 12 March 2013

\section{Introduction}

Insurers face the challenge of operating in insurance markets where potential purchasers have differing risk characteristics. Ideally, insurers correctly distinguish between purchasers' risk types and charge premiums commensurate with risk levels. An insurer's inability to accurately assess purchasers' risk types can result in a situation for the insurer where higher risk types (those with a higher probability of incurring a loss) are able to adversely select against the insurer and purchase insurance at lower rates than they should be theoretically charged.

In competitive markets, adverse selection is addressed through an effective underwriting process that results in the formation of risk pools where the members of each pool share homogeneous risk profiles and characteristics. In situations where insurers are unable to adequately price or classify risk exposures, they can minimise adverse selection by opting not to insure those risks. 
Residual insurance markets are created by state or federal mandate and are designed to be "insurers of last resort" for those who cannot find coverage in the private insurance market. ${ }^{1}$ They exist to provide coverage for residual risk in two settings: (1) where coverage is mandated (e.g., automobile insurance) and (2) for coverage that society deems essential (e.g., health insurance for high risks). ${ }^{2}$ In the United States, every state has residual markets for auto insurance and workers' compensation ${ }^{3}$ with some states having additional residual markets resulting from catastrophe exposure (e.g., residential property coverage in Florida (wind risk) and California (earthquake risk)).

While the rates in the resulting residual market are higher than the rates offered in the state's standard insurance market, they are, in many cases, still insufficient to cover the expected losses from the worst risks in the residual market or 'high risk' pool. Thus, most residual markets are subsidised, but rarely offer sufficient incentive for low risk types to enter since they can obtain lower rates in the private market.

As noted above, residual markets play an important societal and economic function in providing insurance when the standard market is unwilling to provide coverage, or there are disruptions in the standard market that affect pricing and/or availability of coverage. ${ }^{4}$ However, since residual markets are created and often directly supported by governments (state or federal), this leads to a potential financial liability for taxpayers or policyholders depending on the funding mechanism of the residual market. ${ }^{5}$

Further, we argue that some of these residual markets may have significant additional economic costs because of the inability to classify and price risk effectively. If adverse selection is present, it impacts both on the financial viability of the residual market in the short term and on the ability to find equitable solutions for all stakeholders in the long term.

As an example, the Patient Protection and Affordable Care Act (PPACA) provides that individuals who cannot find "affordable" health insurance in the

${ }^{1}$ In this paper, standard insurance markets are also referred to as private insurance markets to differentiate these insurance markets from residual markets that have been created by state or federal government mandates (i.e., public insurance markets).

${ }^{2}$ Browne and Wells (1999).

${ }^{3}$ Harrington and Niehaus (2004).

${ }^{4}$ Coverage may literally be unavailable for some insureds or only available at premium levels that are exorbitant. Pfeffer (1974) notes that one category of risks found in the residual market are those that "are heavily surcharged as substandard or catastrophic".

${ }^{5}$ In some states, all insurance companies who participate in the private insurance market are forced to share in the losses of the residual market. Here, the insurers pass these residual market costs along to all their policyholders. In other situations, the residual market losses are funded on an ex post basis by assessing existing residual market policyholders and policyholders in the standard insurance market. 
private market can opt to participate in a federally funded health insurance plan. If PPACA participation comes from the higher risk (i.e., unhealthy) groups, then it is likely that the public option will be underpriced. If it is sufficiently underpriced, the public option becomes even more attractive and the resulting movement of higher risk individuals into the pool results in an adverse loss experience for the public option plan.

The available options to the plan, then, may not be particularly attractive. If rates are not increased, then taxpayer subsidies in some form are needed as current premium levels would be insufficient to pay claims. If premiums are increased, the public option becomes less attractive to the healthier participants whose participation in the plan becomes increasingly important as they are providing an even greater subsidy to the high-risk participants. Assuming that premium increases for the public option make private market coverage options more attractive for the low-risk group, their departure from the public option plan would create significant ongoing financing and pricing challenges for the plan. It could also provide additional arguments to critics of the PPACA who would likely cite adverse plan performance as further evidence of the weakness of any public option approach and as the basis to repeal all or part of PPACA. The pricing problem described above reflects the inability to correctly classify and price risk within a residual market. As the debate on PPACA certainly will continue regardless of the recent Supreme Court decision affirming the public option plan, a pricing problem within PPACA would likely have a significant impact on future public policy debates involving health-care reform.

The academic literature fails to provide consistent evidence indicating the existence (or lack thereof) of adverse selection. Our paper is unique in that it adds to this literature by investigating the presence of adverse selection in a residual market setting. In order to address this question, the empirical analysis in this paper focuses on the question of whether residual market participants with different risk profiles use their private information to make different insurance purchasing decisions. We use data from a large residual insurance market that provides a public option-type of approach: the state of Florida's public property insurer, Citizens Property Insurance Corporation (Citizens).

Given the significant impact that the hurricane and sinkhole losses have had on the Florida property insurance market both in terms of pricing uncertainty and on insurer decisions to limit or eliminate exposure to loss in the Florida private market, the residual market for property insurance in Florida experienced unprecedented growth during the time period under investigation and thus provides an ideal setting to further explore the presence of adverse selection in residual markets. ${ }^{6}$ If salience surrounding a specific residual market

\footnotetext{
${ }^{6}$ The average sinkhole claim statewide for the period $2006-2010$ was $\$ 56,746$.
} 
is high (e.g., Florida residential property insurance ${ }^{7}$ ) or has the potential to be high (e.g., public health-care option discussed earlier), the presence of adverse selection further exacerbates the problem of finding solutions to address financial shortfalls in residual markets. As a preview of our results, we do find evidence of adverse selection in this residual market.

\section{The development of the Florida residual property market}

The bellwether event for the development of the Florida residual property insurance market was Hurricane Andrew in 1992. With losses more than double the $\$ 6.9$ billion in insured losses from the previous largest catastrophic wind event (Hurricane Hugo in 1989), the losses from Hurricane Andrew resulted in a number of insurer failures and a property insurance availability crisis in Florida. To address these systemic problems, the state legislature created the Florida Hurricane Catastrophe Fund (FHCF) and the Florida Property and Casualty Joint Underwriting Association (FPCJUA). Along with the Florida Windstorm Underwriting Association (FWUA), these organisations collectively represented Florida's residual property insurance market as the FHCF provided mandatory property reinsurance while the FPCJUA and FWUA provided direct property insurance for homes and businesses. ${ }^{8}$

Citizens is a not-for-profit, tax-exempt government corporation that was created in 2001 by combining the FWUA and the FPCJUA. Citizens has three distinct operational areas. First, the High Risk Account (HRA) for Citizens provides coverage consistent with coverage provided under the FWUA (i.e., coastal property wind coverage). Second, the Personal Lines Account (PLA) provides coverage for inland properties. ${ }^{9}$ The Commercial Lines Account (CLA) provides coverage for commercial residential property. As the insurer of last resort, Citizens was only to provide coverage if an insured had been denied coverage in the primary insurance market. ${ }^{10}$ Since its creation, Citizens has seen a significant increase in policy count and exposure growth due to

${ }^{7}$ Dumm et al. (2010).

${ }^{8}$ The FWUA provided wind coverage to coastal residents while the FPCJUA provided coverage to insureds who were unable to find coverage in the standard market. These were combined to form Citizens in 2001, though the FHCF continues to operate to maintain insurance capacity in Florida in the event of catastrophic hurricane losses.

${ }^{9}$ Since the HRA and PLA both include only residual market insureds, for our purposes, the distinction between the HRA and PLA is not important.

${ }^{10}$ Prior to 2007, Citizens was required to offer rates that were higher than the top 25 insurers in the market. This statute was changed in 2007 so that a policyholder could qualify for coverage by Citizens if the rate charged on his/her policy was 15 per cent higher than the rate charged by Citizens. 
Table 1 Florida hurricane losses (2004-2005)

\begin{tabular}{lccr}
\hline Hurricane & Landfall date & Saffir-Simpson category & Insured losses \\
\hline Charlie & $8 / 13 / 04$ & 4 & $\$ 8.1$ billion \\
Jeanne & $8 / 26 / 04$ & 3 & $\$ 4.2$ billion \\
Ivan & $9 / 16 / 04$ & 5 & $\$ 3.9$ billion \\
Frances & $12 / 17 / 04$ & 2 & $\$ 5.3$ billion \\
Dennis & $7 / 10 / 05$ & 3 & $\$ 1.2$ billion \\
Katrina & $8 / 25 / 05$ & 1 & $\$ 597.4$ million \\
Rita & $9 / 20 / 05$ & 2 & $\$ 11.4$ million \\
Wilma & $10 / 24 / 05$ & 3 & $\$ 7.4$ billion \\
\hline
\end{tabular}

(1) windstorm events, (2) mobile or modular home exposures, and more recently, (3) sinkhole losses, and (4) rate rollbacks.

\section{Recent developments in the Florida residual property market}

The Florida property insurance market experienced several significant shock losses over the past two decades. Prior to the 2004 and 2005 hurricane seasons, the last catastrophic property loss in Florida was from Hurricane Andrew in 1992 with over \$16 billion in insured losses. More recently, Florida experienced very active hurricane seasons in 2004 and 2005. These hurricane seasons were particularly costly with combined losses more than double the losses from Hurricane Andrew (see Table 1). In 2004, hurricane losses in Florida were both extensive (in excess of $\$ 20$ billion) and widespread, as hurricane damage affected many parts of the state. While losses in 2005 were less severe than 2004, the losses were still substantial and were in excess of homeowners' insurance premiums collected. On the heels of the hurricane activity in 2004 and the subsequent destruction from Hurricane Katrina, pricing uncertainty for all coastal markets increased significantly.

While insurer decisions to reduce exposure in the Florida market after 2005 was a main driver for the increase in the number of coastal properties insured by Citizens' HRA, Citizens also saw a large increase in policies inland that were attributable in part to non-renewal activity related to sinkhole losses insured by Citizen's PLA. ${ }^{11}$ Heightened uncertainty related to pricing and future potential

${ }^{11}$ Given the size of the average sinkhole loss, the significance of the non-renewal activity in the residential homeowner market is highlighted by the fact that the sinkhole claims frequency ratio at Citizens more than doubled between 2006 and 2009. In 2009, Citizens reported incurring over $\$ 84$ million in sinkhole losses and expenses in the prior year (2008), yet collected only $\$ 19.6$ million during this time in earned premium to cover those costs. 
The Geneva Risk and Insurance Review

132

Table 2 Florida residual property market policy count (2003-2009)

\begin{tabular}{lccccccc}
\hline & 2003 & 2004 & 2005 & 2006 & 2007 & 2008 & 2009 \\
\hline PLA & 383,280 & 416,529 & 400,573 & 743,592 & 845,857 & 629,467 & 609,652 \\
HRA & 433,056 & 453,765 & 435,401 & 403,509 & 446,181 & 445,200 & 410,436 \\
CLA & 3,919 & 3,702 & 3,297 & 8,841 & 12,911 & 9,570 & 9,126 \\
Totals & 822,258 & 876,000 & 841,276 & $1,157,948$ & $1,306,956$ & $1,086,245$ & $1,031,223$ \\
\hline
\end{tabular}

PLA, HRA, CLA policies represent over 99 per cent of all residual property market policies in Florida.

Source: Citizens Property Insurance Corporation.

Note: PLA $\equiv$ Personal Lines Account, HRA $\equiv$ High Risk Account, CLA $\equiv$ Commercial Lines Account, and Totals reflect all residual property market policies.

losses in the Florida property insurance market accompanied by rate rollbacks for Citizens have led to significant changes in both the geographic composition and size of the state's residual insurance market for property insurance.

Citizens has grown into the largest insurer of residential property in the state (27 per cent market share) and based on premium volume, it is among the top 20 writers of residential property insurance in the United States. Comparatively, State Farm Florida, the second largest insurer for individual residences in the state, has a market share of approximately 12 per cent. Further, in 2007, the Florida legislature substantially reduced the rates that Citizens charged and made it easier for homeowners to qualify to purchase insurance from Citizens.

Citizens saw substantial growth following the legislative changes. This growth no longer came solely from higher risk types since lower risk types were now often able to qualify for access to Citizens and receive more favourable pricing. Given Citizens' mandated rate reductions and the minimal access requirements (e.g., declination by current carrier), Citizens provides an excellent setting in which to examine adverse selection in residual markets. ${ }^{12}$

Table 2 shows the substantial increases in the number of policies held by Citizens since 2003. While the policy counts in recent years show the impact of efforts to reduce the number of exposures in Citizens through take-out activity, the number of policies in the highest risk area (HRA) has remained relatively constant, while the policy count for the PLA is approximately 50 per cent higher than in 2004.

${ }^{12}$ Another significant legislative change in 2007 was to reduce Citizens rates to those that were in effect in 2005. Some have charged that the legislative change to lower the barrier for accessing Citizens has made it more of a competitor in some parts of the Florida property market rather than the "insurer of last resort". While data are not available to directly support or refute this contention, these changes are more recent. As noted in the paper, the test for adverse selection primarily involves data from before this legislative change. 


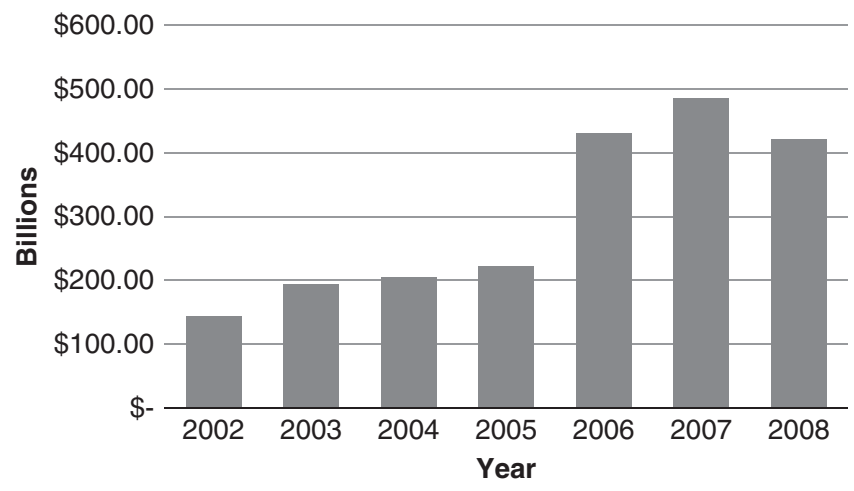

Figure 1. Citizen's insured property values.

Source: Citizens Property Insurance Corporation.

The increased policy count also has drastically increased Citizens' loss exposure. As shown in Figure 1, the year-end exposure almost tripled from approximately $\$ 143$ billion in 2002 to over $\$ 420$ billion in $2008 .{ }^{13}$

Although much of this increase in exposure comes from the high-risk coastal areas, some insureds in lower risk areas may find Citizens' rates to be competitive with their specific insurer. ${ }^{14}$ Table 3 shows direct premiums written for residential property insurance (personal and commercial). Citizens has more than double the market share of the next largest insurer (State Farm Florida) and more market share than the next eight insurers combined.

As noted above, Citizens has seen some decrease in its overall exposure count in PLA but it continues to have significant concentration in the high-risk locations (e.g., Southern Florida) with over 51 per cent of its exposure in Miami-Dade, Broward and Palm Beach counties (Table 4).

13 The HO3 (homeowners form 3) policy provides replacement cost coverage for the dwelling (i.e., coverage to replace the home with a new structure). This coverage feature resulted in Citizens' exposure increasing (marginally) since 2008 even though the underlying market value of the houses insured declined dramatically following the collapse of the residential real estate market in 2008 .

14 This is partially due to regulatory burdens placed on private market insurers by the state. For example, the Florida Commission on Hurricane Loss Projection Methodology was tasked to hold hearings by the Florida legislature in order to determine why insurers in the standard residential property insurance market had adverse loss experience in the absence of any catastrophic wind losses (Florida Commission on Hurricane Loss Projection Methodology, 2010). 
The Geneva Risk and Insurance Review

134

Table 3 Largest Florida residential property insurers (September 30, 2008)

\begin{tabular}{lccc}
\hline Insurer & $\begin{array}{c}\text { Number of } \\
\text { policies }\end{array}$ & $\begin{array}{c}\text { Direct written } \\
\text { premium }\end{array}$ & $\begin{array}{c}\text { Market } \\
\text { share }(\%)\end{array}$ \\
\hline Citizens Property Insurance Corporation & $1,157,568$ & $\$ 2,634,549,525$ & 27 \\
State Farm Florida Insurance Company & 933,140 & $\$ 1,235,634,528$ & 13 \\
Universal Property \& Casualty Insurance & 450,162 & $\$ 520,782,661$ & 5 \\
Company & & & 3 \\
St. Johns Insurance Company, Inc. & 196,159 & $\$ 284,614,156$ & 2 \\
QBE Insurance Corporation & 3,290 & $\$ 213,634,023$ & 2 \\
Royal Palm Insurance Company & 129,481 & $\$ 212,696,314$ & 2 \\
United Services Automobile Association & 167,958 & $\$ 206,889,858$ & 2 \\
Liberty Mutual Fire Insurance Company & 101,617 & $\$ 167,524,690$ & 2 \\
Homewise Preferred Insurance Company & 106,648 & $\$ 165,946,316$ & 2 \\
Florida Peninsula Insurance Company & 94,962 & $\$ 156,716,480$ & 59 \\
TOTAL - Largest 10 residential property & $3,340,985$ & $\$ 5,798,988,551$ & 100 \\
writers & & & \\
TOTAL - All residential property writers & $6,115,030$ & $\$ 9,786,050,514$ & \\
\hline
\end{tabular}

Source: Citizens Property Insurance Corporation.

Table 4 Florida residual market high risk account concentration (September 30, 2008)

\begin{tabular}{lcccccc}
\hline County & $P R-M$ & Wind-only & CR-M & Policies inforce & $\%$ & Cumulative (\%) \\
\hline Miami-Dade & 14,203 & 75,626 & 140 & 89,969 & 19.8 & 19.8 \\
Broward & 12,452 & 64,092 & 99 & 76,643 & 16.9 & 36.8 \\
Palm Beach & 9,610 & 56,097 & 66 & 65,773 & 14.5 & 51.3 \\
Sarasota & 6,951 & 36,703 & 5 & 43,659 & 9.6 & 60.9 \\
Monroe & 708 & 26,306 & 5 & 27,019 & 6.0 & 66.9 \\
Volusia & 4,537 & 19,404 & 0 & 23,941 & 5.3 & 72.1 \\
Lee & 2,459 & 18,924 & 8 & 21,391 & 4.7 & 76.9 \\
Pinellas & 2,539 & 14,366 & 9 & 16,914 & 3.7 & 80.6 \\
Pasco & 5,769 & 6,127 & 2 & 11,898 & 2.6 & 83.2 \\
Collier & 1,080 & 10,214 & 5 & 11,299 & 2.5 & 85.7 \\
State Total & 68,128 & 384805 & 397 & 453,330 & & \\
\hline
\end{tabular}

Source: Citizens Property Insurance Corporation (Total Counties $=67$ ).

Note: PR-M $\equiv$ Personal Residential Multi-Peril; CR-M $\equiv$ Commercial Residential Multi Peril.

\section{Adverse selection and the insurance purchase decision}

Adverse selection is a problem of asymmetric information in that the true risk level of the insured is hidden from the insurer. Insureds are presumed to know more about their true risk level than an insurer. ${ }^{15}$ For example,

\footnotetext{
15 Doherty (2000, p. 72) provides a comprehensive definition and discussion of adverse selection as it applies to insurance markets.
} 
insureds have a better idea of their health levels, their driving ability, as well as the quality of their home. Insurers use the underwriting process in an attempt to minimise the information asymmetries (e.g., the insurance application). Another method commonly considered to minimise information asymmetries between insurers and insureds is the use of deductibles. Theoretically, when an insured chooses a higher deductible it is thought to be a signal of a high quality (low risk) insured ${ }^{16}$ If an insured believed he was a bad risk, he would be inclined to choose a lower deductible, thus minimising the amount he would be required to pay in the event of an accident. Citizens offers its customers three deductible levels. To test for the existence of adverse selection, this paper will exploit these options in an attempt to determine if those insureds choosing a lower deductible level are more susceptible to having higher losses. ${ }^{17}$

\section{Related research}

There are two main strands of research related to our study, residual insurance markets and adverse selection. The literature on residual insurance markets is relatively limited compared with literature on adverse selection that includes not only theoretical works but also empirical papers that investigate markets outside of insurance. Since our paper is an empirical investigation of the possible existence of adverse selection in a particular residual insurance market, we focus our discussion of adverse selection literature on empirical insurance studies.

\section{Residual insurance markets}

Early discussion of residual insurance markets provides rationale for the existence of such markets, examines how countries manage residual risks and considers the appropriate role of government. While residual risks are primarily created as a result of insurer underwriting standards and strategies, this does not necessarily make these risks uninsurable. Pfeffer ${ }^{18}$ compares the insurance industry treatment of residual risks in many western European countries with approaches utilised in the U.S. He finds no evidence of a residual market problem in the European countries based on a number of socioeconomic and political factors. Broader

\footnotetext{
${ }^{16}$ Rothschild and Stiglitz (1976).

${ }^{17}$ It is important to note that deductibles also are used to minimise moral hazards (i.e., encourage proper behaviour) of insureds. We further discuss distinguishing between adverse selection and moral hazard in a subsequent section.

${ }^{18}$ Pfeffer (1974).
} 
underwriting classification employed by European insurers also helps facilitate residual risks. Pfeffer ${ }^{18}$ concludes that any residual risk problem can be solved by cooperation between private insurers and government where insurance is obtained by all prospects with redistribution of the risk by means of some form of reinsurance (e.g., government- or industry-based high-risk pools).

Greene $^{19}$ suggests the "residual market philosophy" as the strongest of five rationales for the establishment of any type of government insurance programme. ${ }^{20}$ This philosophy is simply a proposed justification for government participation in insurance because private insurers are either unable or unwilling to supply certain insurance needs legitimately demanded by the public. This philosophy implies that insurability requirements are different and commonly less strict for government insurers than for private insurers (e.g., covering catastrophic losses in a given geographic area). Greene ${ }^{19}$ cites the federal flood insurance programme, the federal crime insurance programme, workers compensation and unemployment insurance as examples of government insurance programmes whose establishment was motivated by the residual market philosophy. However, the author suggests that while some type of government involvement in insurance is desirable, some types of existing government insurance are unjustifiable as these insurance needs should be met by private insurers.

Carroll and Kaestner, Kwon and Grace, Kaestner and Carroll, Harrington and Danzon, and Danzon and Harrington ${ }^{21}$ provide a non-exhaustive list of papers that utilise workers compensation (WC) insurance markets to investigate the economic effects of various regulatory and political actions. Several of these articles directly compare the residual WC market with the voluntary WC market in their investigations. For example, Danzon and Harrington ${ }^{22}$ hypothesise that insurance rate suppression exacerbates loss growth and ultimately leads to higher insurance premiums. They test their predictions using WC insurance data from eight states from 1985 to 1991, a time when many regulators denied insurer requests for $\mathrm{WC}$ rate increases that were motivated by rapidly rising WC loss costs. Insurers responded by reducing the proportion of risks accepted in the voluntary WC market and assigning the remaining risks to the residual WC market. Danzon and Harrington ${ }^{22}$ empirically show that the loss-increasing effects were higher in the residual WC market than in the voluntary WC market, but the premium increased more

\footnotetext{
${ }^{19}$ Greene (1976).

${ }^{20}$ The other four rationales Greene (1976) proposes are: the convenience motive, the need for compulsion, the motive of greater efficiency and the need to achieve collateral social purposes.

${ }^{21}$ Carroll and Kaestner (1995); (Kwon and Grace (1996); Kaestner and Carroll (1997); Harrington and Danzon (2001) and Danzon and Harrington (2001).

${ }^{22}$ Danzon and Harrington (2001).
} 
rapidly in the voluntary WC market. Further, the authors find empirical evidence of cross subsidies at the state level between and within WC rating classes where high risks and small firms are subsidised by low risks and insurer equity.

\section{Adverse selection in insurance markets}

Theoretical and empirical papers on insurance markets have shown that adverse selection may reduce insurance consumption (by low-risk buyers), may result in a wealth transfer from low-risk buyers to high-risk buyers or may lead to eventual market failure. Seminal theoretical papers of Akerlof, Rothschild and Stiglitz, Miyazaki, Wilson and Spence ${ }^{23}$ develop various equilibrium models characterised by asymmetric information. For example, in an insurance market setting, Rothschild and Stiglitz ${ }^{16}$ establish a separating equilibrium where lowrisk and high-risk buyers purchase different insurance products. Miyazaki and Spence $^{24}$ establish cross-subsidisation equilibrium where low-risk buyers subsidise high-risk buyers. Finally, Wilson ${ }^{25}$ describes a pooling equilibrium where low-risk and high-risk buyers purchase the same policy so that the low-risk buyers actually subsidise the insurance purchases of the high-risk buyers. These theoretical papers laid the foundation for designing empirical tests of adverse selection in private insurance markets.

Our paper is an empirical test of adverse selection in a specific type of insurance market, the residual property insurance market in Florida. Hence, empirical papers that examine adverse selection in various insurance markets are of particular interest to us. ${ }^{26}$ With respect to homeowners' insurance, an unpublished working paper, Aarbu, ${ }^{27}$ is the only study we are aware of that examines adverse selection in homeowners' markets. Using a parametric test similar to ours, and data from a Norwegian homeowners' carrier, Aarbu ${ }^{27}$ finds results consistent with adverse selection in the Norwegian market. Our study differs from $\mathrm{Aarbu}^{27}$ in that we use both parametric and non-parametric tests, and we examine the residual homeowners' market. Browne ${ }^{28}$ and Browne and Doerpinghaus ${ }^{29}$ are two studies that test for adverse selection in the private

\footnotetext{
23 Akerlof (1970); Rothschild and Stiglitz (1976); Miyazaki (1977); Wilson (1977) and Spence (1978).

24 Miyazaki (1977) and Spence (1978).

${ }^{25}$ Wilson (1977).

${ }^{26}$ Cohen and Siegelman (2010) provide a recent review of the empirical literature on insurance markets and adverse selection.

27 Aarbu (2010).

${ }^{28}$ Browne (1992).

29 Browne and Doerpinghaus (1993).
} 
health insurance market and attempt to determine what form of equilibrium exists in this market. Browne ${ }^{28}$ finds that low-risk buyers obtain more coverage in the group health insurance market than in the individual health insurance market; a result consistent with the presence of adverse selection in the individual market. Browne ${ }^{28}$ also finds an equilibrium where low-risk buyers subsidise high-risk buyers in the individual market; a result consistent with the pooling equilibrium models of Wilson and Miyazaki. ${ }^{30}$ Browne and Doerpinghaus ${ }^{29}$ also find evidence of adverse selection in the individual health insurance market as (unobservable) high-risk buyers purchase insurance policies with similar cost sharing provisions as low-risk buyers. Since the high-risk insureds ultimately receive more indemnity benefits per premium dollar than the low risks, this pooling equilibrium also suggests that low-risk insureds subsidise the insurance purchase of the high-risk insureds. The result resembles the equilibrium proposed by Wilson. ${ }^{25}$

Dahlby ${ }^{31}$ tests for adverse selection in the private automobile insurance market and attempts to determine what form of equilibrium exists in this market. Dahlby ${ }^{31}$ models the purchase of collision insurance (a voluntary coverage) to successfully test for the existence of adverse selection in the Canadian auto insurance market. Dahlby ${ }^{31}$ also simulates how this market would react with the removal of gender discrimination from the insurance pricing formula. Here, he finds that premiums for single female drivers would significantly increase, although a significant proportion of the single female drivers would no longer obtain collision insurance.

Finally, Makkin, and Somwaru and Finkelstein and Poterba ${ }^{32}$ are examples of empirical studies that find evidence of adverse selection in the crop insurance market and annuity market, respectively. There also exist a number of empirical papers that find little or no evidence of adverse selection in the same types of insurance markets. ${ }^{33}$ We next develop our hypothesis and describe the residual market data we use to investigate the presence of adverse selection in Florida's residual property insurance market.

\section{Adverse selection vs. moral hazard}

A problem noted in many adverse selection papers (including Chiappori and Salanié ${ }^{34}$ ) is the inherent difficulty in distinguishing between adverse selection and moral hazard. Both information asymmetry problems can result in the

\footnotetext{
${ }^{30}$ Wilson (1977) and Miyazaki (1977).

${ }^{31}$ Dahlby (1983).

32 Makki and Somwaru (2001) and (Finkelstein and Poterba, 2004).

${ }^{33}$ Chiappori and Salanié (2000); Cawley and Philipson (1999) and Cardon and Hendel (2001).

${ }^{34}$ Chiappori and Salanié (2000).
} 
same observable outcome, particularly, insureds with lower (higher) deductibles have higher (lower) costs with respect to losses. ${ }^{35}$ When dealing with automobile and health insurance, this is particularly difficult to disentangle. That is, it is harder to determine whether or not the insurance is creating the moral hazard problem, or adverse selection within the insured group is creating the problem. We propose that by using homeowners' insurance, we resolve this problem. The nature of the insured property (the home) makes buying homeowners' insurance less susceptible to moral hazard (though not impossible). From an ex ante moral hazard standpoint, it is hard to imagine a homeowner changing the risk profile of the home after the purchase of insurance. ${ }^{36}$ Although ex post moral hazard is also a concern for insurers, the tests we employ (consistent with the academic literature) focus on the probability of a loss and not the ultimate loss amount. ${ }^{37}$ Conversely, it is not hard to imagine a homeowner having private information regarding the risk of the home prior to purchasing insurance. Finally, in his study, Aarbu ${ }^{27}$ finds support for evidence of adverse selection, rather than moral hazard, in the Norwegian homeowners' market.

\section{Hypothesis and data}

The primary hypothesis of this paper is that significant adverse selection is occurring in the residual property insurance market in the state of Florida. Particularly, we predict that individuals who generally consider themselves high risk are choosing more coverage in the form of lower deductibles. In the existing insurance and economics literature, finding consistent evidence of adverse selection in insurance markets has proven to be difficult. Although numerous papers find evidence of adverse selection in health insurance, automobile markets and annuity markets (Browne, Puelz and Snow, and

\footnotetext{
${ }^{35}$ With respect to moral hazard, this problem can arise from insureds changing their behaviour before a loss occurs (ex ante moral hazard) to affect the likelihood of loss or severity of loss, or from insureds changing their behaviour after a loss to increase the loss amount (ex post moral hazard).

${ }^{36}$ Indeed, in our sample data, almost half of the losses paid by Citizens ( 46.5 per cent of the number of claims and 46.8 per cent of the claim dollars) resulted from hurricane-related wind risks. Risks that could be more susceptible to moral hazard (burglary, cooking fires, freezing and theft) constituted less than 6 per cent of claims dollars.

${ }^{37}$ Technically, we define the occurrence of a loss if the claim amount exceeds a certain threshold (the highest deductible amount). The only situation in which our tests confound ex post moral hazard with adverse selection is if there are a lot of completely fraudulent claims (i.e., the true loss is zero). Even if the claims are fraudulently padded, the loss is still valid.
} 
140

Finkelstein and Poterba ${ }^{38}$ to name a few), there exist an equal number of papers which find no evidence, often in the same markets. ${ }^{39,40}$

To test for adverse selection in Florida's residential residual property market, this paper will utilise data from policies issued by Citizens between 2002 and 2007. In addition to policy information on each policy issued, property information for the applicable insured property also has been collected. As illustrated above, the time period studied includes two years (2004 and 2005) with significant hurricane activity. Data for all losses (including non-hurricane losses) also have been collected and matched with the new policies issued. In sum, data on approximately 2.1 million new policies have been collected. Roughly 4 per cent of these new policies suffered losses during the period of study. Data including loss amounts as well as characteristics of the insured property will allow for rigorous testing for evidence of adverse selection in this residual market.

The actual testing of the existence of adverse selection is a test on the conditional independence of the choice of a lower deductible and the existence of a loss by an insured. As in Chiappori and Salanie ${ }^{34}$ the test is conditioned on characteristics observed by the insurer. If there exists no adverse selection, then the choice of a lower deductible and the existence of a loss will be independent. ${ }^{41}$ However, if these outcomes are not independent, then evidence of adverse selection would exist.

\section{Methodology and results}

We make extensive use of the methodology of Chiappori and Salanié ${ }^{34}$ and utilise both parametric and nonparametric methods. Our parametric test involves estimating two probit models meant to model the deductible choice as well as the accident probability. Our nonparametric tests are all based on the $\chi^{2}$ test of independence.

We first estimate the following two probit models:

$$
y_{i}=1\left(X_{i} \beta+\varepsilon_{i}>0\right)
$$

\footnotetext{
${ }^{38}$ Browne (1992); Puelz and Snow (1994) and Finkelstein and Poterba (2004).

${ }^{39}$ Chiappori and Salanié (2000); Cawley and Philipson (1999) and Cardon and Hendel (2001).

${ }^{40}$ Puelz and Snow (1994) attempt to empirically determine whether adverse selection is present in the state of Georgia's individual automobile collision insurance market. Although Puelz and Snow (1994) find no evidence of cross-subsidisation between the contracts of different risk classes, their model has been criticised by Chiappori and Salanié (2000) and Dionne et al. (2001).

${ }^{41}$ A reviewer also notes that independence could be consistent with the existence of "advantageous selection" as noted by de Meza and Webb (2001).
} 
and

$$
z_{i}=1\left(X_{i} \gamma+\eta_{i}>0\right)
$$

where $y_{i}$ is a binary variable equal to one to if an individual chooses a "low deductible" of $\$ 500$ or $\$ 1,000$ on their homeowners' policy and zero if the deductible is $\$ 2,500$. As in Hagmayer et al., ${ }^{42} z_{i}$ is a binary variable equal to one if an individual has suffered at least one loss in our data period greater than the highest deductible, $\$ 2,500 .^{43}$ Finally, $X_{i}$ is a vector of exogenous variables related to the riskiness of the individual and $\varepsilon_{i}$ and $\eta_{i}$ are the random error terms. The observations are further weighted by the length of time during which the policy was in force during the year $\left(w_{i}\right)$. As in Chiappori and Salanié, ${ }^{34}$ we then estimate the generalised residuals, $\hat{\varepsilon}_{i}$ and $\hat{\eta}_{i}$, of $\varepsilon_{i}$ and $\eta_{i}$ and generate the following test statistic:

$$
W=\frac{\left(\sum_{i=1}^{n} w_{i} \hat{\varepsilon}_{i} \hat{\eta}_{i}\right)^{2}}{\sum_{i=1}^{n} w_{i}^{2} \hat{\varepsilon}_{i}^{2} \hat{\eta}_{i}^{2}} .
$$

Gouriéroux et al. $^{44}$ show that our test statistic $W$ is asymptotically distributed as a $\chi^{2}(1)$ under the null hypothesis of conditional independence of the residuals (i.e., $\operatorname{cov}\left(\varepsilon_{i}, \eta_{i}\right)=0$ ).

We estimate models (1) and (2) using the exogenous variables relayed to us by underwriters at Citizens to be most important in the underwriting process. Specifically, we include the following variables: (1) age of the home, (2) insured value of the home (the limit of insurance on the primary dwelling, corresponding to the Coverage A insuring agreement of the HO3 form), and (3) the number of stories of the home. We also include several binary variables including (the number of variables is in parenthesis): (1) binary variables related to the rating territory $(110)$, (2) binary variables related to the construction of the home (frame, masonry or trailer) (3), (3) binary variables related to the attachment of the roof decking (3), (4) binary variables related to the roof shape (3), (5) binary variables related to the roof to wall attachment (4), (6) binary variables related to the protection of openings (e.g., doors and

\footnotetext{
${ }^{42}$ Hagmayer et al. (2012).

43 A referee notes that setting $z_{i}$ equal to one only if an individual reports a loss may introduce spurious correlation since low deductible insureds will be able to make more claims simply because the losses exceed the deductible at lower levels of losses. Ultimately, the threshold does not matter, as the results are significant at the 1 per cent level with any reasonable threshold.

${ }^{44}$ Gouriéroux et al. (1987).
} 
The Geneva Risk and Insurance Review

142

Table 5 Summary Statistics

\begin{tabular}{|c|c|c|c|c|c|}
\hline Variable & Mean & Median & $\begin{array}{l}\text { Standard } \\
\text { deviation }\end{array}$ & Min. & Max. \\
\hline Loss & 0.0431 & 0 & 0.2030 & 0 & 1 \\
\hline Low Deductible & 0.7956 & 1 & 0.4033 & 0 & 1 \\
\hline Coverage A (policy limit (\$)) & $140,186.31$ & 131,900 & $94,228.70$ & 0 & $5,046,135$ \\
\hline Age (years) & 30.1018 & 29 & 18.2827 & 0 & 186 \\
\hline Size (square feet) & $1,498.96$ & 1387 & 634.5270 & 0 & 9999 \\
\hline Number of Stories & 1.4045 & 1 & 2.3070 & 0 & 337 \\
\hline Frame & 0.0915 & 0 & 0.2883 & 0 & 1 \\
\hline Masonry & 0.7400 & 1 & 0.4386 & 0 & 1 \\
\hline Mobile Home & 0.1444 & 0 & 0.3515 & 0 & 1 \\
\hline RoofDeck (Plywood) & 0.8478 & 1 & 0.3592 & 0 & 1 \\
\hline RoofDeck (Metal) & 0.0116 & 0 & 0.1069 & 0 & 1 \\
\hline RoofDeck (Concrete) & 0.0321 & 0 & 0.1763 & 0 & 1 \\
\hline Flat Roof & 0.3608 & 0 & 0.4802 & 0 & 1 \\
\hline Gable Roof & 0.4304 & 0 & 0.4951 & 0 & 1 \\
\hline Hip Roof & 0.1029 & 0 & 0.3038 & 0 & 1 \\
\hline RoofWall (Clips) & 0.0052 & 0 & 0.0722 & 0 & 1 \\
\hline RoofWall (Double Wrap) & 0.0033 & 0 & 0.0576 & 0 & 1 \\
\hline RoofWall (Single Wrap) & 0.0341 & 0 & 0.1815 & 0 & 1 \\
\hline RoofWall (Toe-Nail) & 0.8023 & 1 & 0.3982 & 0 & 1 \\
\hline OpenCov (Class A) & 0.0337 & 0 & 0.1805 & 0 & 1 \\
\hline OpenCov (Class B) & 0.0024 & 0 & 0.0486 & 0 & 1 \\
\hline OpenCov (Class C) & 0.0225 & 0 & 0.1482 & 0 & 1 \\
\hline OpenCov (None) & 0.8523 & 1 & 0.3548 & 0 & 1 \\
\hline Superior Construction & 0.0119 & 0 & 0.1085 & 0 & 1 \\
\hline ProtectionClass1-6 & 0.9508 & 1 & 0.2162 & 0 & 1 \\
\hline ProtectionClass 7 & 0.0055 & 0 & 0.0738 & 0 & 1 \\
\hline ProtectionClass8 & 0.0012 & 0 & 0.0351 & 0 & 1 \\
\hline ProtectionClass9 & 0.0371 & 0 & 0.1889 & 0 & 1 \\
\hline ProtectionClass 10 & 0.0051 & 0 & 0.0712 & 0 & 1 \\
\hline ProtectionClass 11 & 0.0003 & 0 & 0.0177 & 0 & 1 \\
\hline Coastal & 0.3817 & 0 & 0.4858 & 0 & 1 \\
\hline
\end{tabular}

windows) (4), (7) a binary variable equal to one if the home meets a "superior construction" designation, (8) binary variables related to the proximity of fire stations (6), and (9) a binary variable equal to one if the home is in the coastal region. In all, we utilise 138 exogenous variables in models (1) and (2). Summary statistics for the sample can be found in Table 5.

We do not report the individual coefficients of the models (though, they are available upon request). However, the models themselves are significant and only a handful of the exogenous variables are not significant at the 10 per cent level or better. Our $W$ statistic is 52.942. The critical value of $\chi^{2}(1)$ at 1 per cent significance is 6.63 , which suggests a fairly strong rejection of independence. 
As Chiappori and Salanie ${ }^{34}$ point out, the use of the above test can introduce bias in "unpredictable ways". We again follow their procedure and produce three tests based on the standard $\chi^{2}$ test of independence. If we consider $x_{i}$ to be a set of $m$ exogenous categorical variables, with $c_{i}$ categories, we can separate our data into bins where every house shares the same value for each of the variables. We then have unique bins in which we generate the following table:

\begin{tabular}{lcc}
\hline & Bins & \\
\hline & $z_{i}=0$ & $z_{i}=1$ \\
\hline$y_{i}=0$ & $N_{00}$ & $N_{01}$ \\
$y_{i}=1$ & $N_{10}$ & $N_{11}$ \\
\hline
\end{tabular}

where $z_{i}$ and $y_{i}$ are defined as the deductible choice and the loss variables described above. In order to implement this procedure, we have to consider the trade-off between having too few observations in each bin and having a finer categorisation of our observations. We apply the following categories to our data (the number in parenthesis is the number of categories):

1. age-based categories (3)

2. whether the home is in a coastal region (2)

3. size of the home (2)

4. roof shape (2)

5. value of the home (2)

This then gives us a total of 48 bins. We again follow Chiappori and Salanie $^{34}$ and calculate the following test statistic for each bin:

$$
T=\sum_{j, k=0,1} \frac{\left[N_{j k}-\left(N_{j .} N_{. k} N_{. .}\right)\right]^{2}}{N_{j k}},
$$

where $N_{j}$. is defined to be $N_{j 0}+N_{j 1}, N_{. j}$, is defined to be $N_{0 j}+N_{1 j}$, and $N$. is defined to be $N_{._{0}}+N_{\cdot_{1}}$. If $y_{i}$ and $z_{i}$ are independent within each bin, our test statistic $T$ is again asymptotically distributed as a $\chi^{2}(1)$.

We have $C=48$ test statistics (the number of bins) on which we then conduct the same three tests as Chiappori and Salanié. ${ }^{34}$ First, we conduct the Kolmogorov-Smirnov test on the empirical cumulative density function $\hat{F}_{C}$. We calculate the standard Kolmogorov-Smirnov test statistic:

$$
D=\sup _{x}\left|\hat{F}_{C}(x)-F(x)\right|
$$


where $F$ denotes the cumulate density function of a $\chi^{2}(1)$. The critical value of this statistic at the 1 per cent level is $\frac{1.63}{\sqrt{C}} .45$

Next, we simply count the number of bins in which we would reject independence. That is, if the $T$ statistic is greater than 3.84 (the critical value of $\chi^{2}$ at 5 per cent confidence), we would reject independence. Under conditional independence, the number of rejections is binomially distributed $B(C, 0.05)$. Finally, we sum the individual $T$ statistics. Under conditional independence, this sum is distributed as a $\chi^{2}$ with $C$ degrees of freedom.

Although our categories were chosen to provide as much detail as possible while also allowing adequate population of the bins, there were a few bins that did not provide sufficient numbers to calculate the test statistic $T$. In all, we have 40 usable statistics. As in the parametric test, all three tests reject the null hypothesis of conditional independence. The $D$ statistic is 0.4247 which is well above the critical value at 1 per cent of 0.2577 . Further, in 17 of the 40 bins the test statistic $T$ is greater than the 3.84 critical value. We would reject conditional independence at any level for $B(C, 0.05)$. Finally, the sum of our $T$ statistics is 6242.92 which is well above the critical value at the 1 per cent level of 63.69 (from $\chi^{2}(40)$ ).

Ultimately, all four of our tests, both parametric and nonparametric, strongly reject the null hypothesis of conditional independence. That is, there seems to be a strong relationship between the deductible choice and loss experience, suggesting adverse selection.

\section{Conclusion}

Adverse selection is a problematic issue for insurers. If an insurer is not properly pricing its products, some insureds will purchase insurance at actuarially unfair rates and create larger than expected losses for the insurer. The academic literature has not found consistent evidence indicating the existence (or lack thereof) of adverse selection in various insurance markets. Our paper adds to this literature as we find evidence of adverse selection in Florida's residual homeowners' market. To the best of our knowledge, this is the first empirical adverse selection study to explore the residual risk market. Specifically, we use the methodology of Chiappori and Salanié ${ }^{34}$ to show a relationship between the deductible choice and loss experience of homeowners in Florida's residual market. We find that while controlling for the risk level of insureds, those with a higher likelihood of a loss choose lower deductibles (i.e., more insurance). This relationship is evidence of adverse selection in Florida's residual homeowners' market.

\footnotetext{
${ }^{45}$ Klugman et al. (1998).
} 
Given the size of the exposures in Citizens and the financial implication for the residents of the state of Florida in the event of a large catastrophic wind loss, it is not surprising that there is significant concern about the level of these exposures. A significant debate in Florida relates to the overall pricing of Citizens. The findings of this paper indicate that in addition to the external challenges that Citizens faces in setting rates vis-à-vis the standard market, the internal challenges of pricing of risks within Citizens is also problematic. In addition to rate differentials, consideration should be given to further address Citizens' adverse selection problem by increasing the risk borne by the highrisk members of the pool in some manner (e.g., higher deductibles). As such, public policy decisions need to focus on the adverse risks inside of the residual market to lessen the impact of the worst risk on Citizens, and ultimately limit the financial burden of other policyholders in the state.

Finally, this paper also extends the academic literature by empirically investigating adverse selection in the large residual market setting where the public policy issues related to intra-market (standard to residual) continue to be hotly debated. Although our research focuses on the property market, there are other residual markets (e.g., health insurance) where the presence of adverse selection also can have a significant impact on both the public policy debate and the political decisions made as a by-product of that debate.

\section{References}

Aarbu, K.O. (2010) Asymmetric Information-Evidence from the Home Insurance Market, Norwegian School of Economics and Business Administration Discussion Paper.

Akerlof, G.A. (1970) 'The market for "lemons": Quality uncertainty and the market mechanism', Quarterly Journal of Economics 84(3): 488-500.

Browne, M.J. (1992) 'Evidence of adverse selection in the individual health insurance market', The Journal of Risk and Insurance 59(1): 13-33.

Browne, M.J. and Doerpinghaus, H.I. (1993) 'Information asymmetries and adverse selection in the market for individual medical expense insurance', The Journal of Risk and Insurance 60(2): 300-312.

Browne, M.J. and Wells, B.P. (1999) 'Claims adjudication in the personal automobile insurance residual market', The Journal of Risk and Insurance 66(2): 275-290.

Cardon, J.H. and Hendel, I. (2001) 'Asymmetric information in health insurance: Evidence from the national medical expenditure survey', The RAND Journal of Economics 32(3): 408-427.

Carroll, A.M. and Kaestner, R. (1995) 'The relationship between regulation and prices in the workers' compensation insurance market', Journal of Regulatory Economics 8(2): $149-166$.

Cawley, J. and Philipson, T. (1999) 'An empirical examination of information barriers to trade in insurance', The American Economic Review 89(4): 827-846.

Chiappori, P.-A. and Salanié, B. (2000) 'Testing for asymmetric information in insurance markets', The Journal of Political Economy 108(1): 56-78. 
Cohen, A. and Siegelman, P. (2010) 'Testing for adverse selection in insurance markets', Journal of Risk and Insurance 77(1): 39-84.

Dahlby, B.G. (1983) 'Adverse selection and statistical discrimination: An analysis of Canadian automobile insurance', Journal of Public Economics 20(1): 121-130.

Danzon, P.M. and Harrington, S.E. (2001) 'Workers' compensation rate regulation: How price controls increase costs', Journal of Law and Economics 44(1): 1-36.

de Meza, D. and Webb, D.C. (2001) 'Advantageous selection in insurance markets', The RAND Journal of Economics 32(2): 249-262.

Dionne, G., Gouriéroux, C. and Vanasse, C. (2001) 'Testing for evidence of adverse selection in the automobile insurance market: A comment', Journal of Political Economy 109(2): $444-453$.

Doherty, N.A. (2000) Integrated Risk Management, New York: McGraw-Hill.

Dumm, R.E., Liebenberg, A.P., Liebenberg, I.A. and Ruhland, J.S. (2010) 'Market reaction to regulatory capture and political risk in a highly-salient environment', Journal of Insurance 28(2): 141-166.

Finkelstein, A. and Poterba, J. (2004) 'Adverse selection in insurance markets: Policyholder evidence from the U.K. annuity market', The Journal of Political Economy 112(1): 183-208.

Florida Commission on Hurricane Loss Projection Methodology (2010) Windstorm Mitigation Discounts Report, pp. 1-40.

Gouriéroux, C., Monfort, A., Renault, E. and Trognon, A. (1987) 'Generalised residuals', Journal of Econometrics 34(1-2): 5-32.

Greene, M.R. (1976) 'The government as an insurer', The Journal of Risk and Insurance 43(3): 393-407.

Hagmayer, S., Spindler, M. and Winter, J. (2012) Asymmetric information in the market for automotive insurance: Evidence from Germany, Working Paper.

Harrington, S.E. and Danzon, P.M. (2001) 'Rate regulation, safety incentives and loss growth in workers' compensation insurance', Journal of Business 73(4): 569-595.

Harrington, S.E. and Niehaus, G.R. (2004) Risk Management and Insurance, 2nd edn, Boston: McGraw-Hill Irwin.

Kaestner, R. and Carroll, A. (1997) 'New estimates of the labor market effects of workers' compensation insurance', Southern Economic Journal 63(3): 635-651.

Klugman, S.A., Panjer, H.H. and Willmot, G.E. (1998) Loss Models: From Data to Decisions, New York: Wiley.

Kwon, W.J. and Grace, M.F. (1996) 'Examination of cross subsidies in the workers' compensation market', Journal of Insurance Regulation 15(2): 256-289.

Makki, S.S. and Somwaru, A. (2001) 'Evidence of adverse selection in crop insurance markets', The Journal of Risk and Insurance 68(4): 685-708.

Miyazaki, H. (1977) 'The rat race and internal labor markets', The Bell Journal of Economics 8(2): $394-418$.

Pfeffer, I. (1974) 'Residual risks in Europe', The Journal of Risk and Insurance 41(1): 41-56.

Puelz, R. and Snow, A. (1994) 'Evidence on adverse selection: Equilibrium signaling and cross-subsidization in the insurance market', The Journal of Political Economy 102(2): 236-257.

Rothschild, M. and Stiglitz, J. (1976) 'Equilibrium in competitive insurance markets: An essay on the economics of imperfect information', The Quarterly Journal of Economics 90(4): 629.

Spence, M. (1978) 'Product differentiation and performance in insurance markets', Journal of Public Economics 10(3): 427-447.

Wilson, C. (1977) 'A model of insurance markets with incomplete information', Journal of Economic Theory 16(2): 167-207. 


\begin{abstract}
About the Authors
Randy E. Dumm is the Hold Professor of Risk Management and Insurance at Florida State University. He received his PhD from The University of Georgia and joined the risk management and insurance faculty at Florida State University in 1997. His research interests include insurance regulation, insurer operations, insurance distribution channels, catastrophic loss models and life insurer products.
\end{abstract}

David L. Eckles is Associate Professor of Risk Management and Insurance in the Terry College of Business at the University of Georgia. He received his $\mathrm{PhD}$ in risk management and insurance from the Wharton School of the University of Pennsylvania. His research interests are focused in the areas of insurance company operations, corporate governance, insurer efficiency and insurance markets. He thanks the Terry-Sanford Summer Research Award Program for funding related to this project.

Martin Halek has been a member of the Actuarial Science, Risk Management and Insurance Department of the School of Business at the University of Wisconsin-Madison since 2008. He received his PhD degree in risk management and insurance from the Wharton School of the University of Pennsylvania. His research interests are focused in the areas of insurance economics, insurer ratings and financial markets, insurer loss reserves, and hazard risk assessment. 